\title{
Capsule Commentary on Wolf et al., A Patient-Centered Prescription Drug Label to Promote Appropriate Medication Use and Adherence
}

\author{
Fabrice Smieliauskas, $P h D$ \\ Department of Public Health Sciences, University of Chicago, Chicago, IL, USA.
}

J Gen Intern Med 31(12):1507

DOI: $10.1007 / \mathrm{s} 11606-016-3854-4$

() Society of General Internal Medicine 2016

$\mathrm{T}$ his randomized, unblinded pragmatic trial ${ }^{1}$ tested the effectiveness of changing prescription drug labels from a current standard (e.g., 'take 1 tablet twice daily') to a "Universal Medication Schedule" (UMS) that displays specific times of day (e.g., morning, noon, evening, bedtime) when prescriptions should be taken, and is formatted in a patientfriendly way. Participants were 845 type 2 diabetes patients at safety net clinics currently taking two or more oral medications and speaking English or Spanish. Results were that patients receiving UMS-labelled drugs were more likely to be able to demonstrate proper use of medications to investigators at 9 months, though not at 3 months, with no statistically significant overall effects on adherence rates measured either by self-report or pill count. While there was suggestive evidence of stronger effects in vulnerable patient subgroups (those with more frequent doses, polypharmacy, or limited literacy skills), results were not consistently significant across outcome measures.

The lack of blinding, combined with the patientreported nature of the outcomes, raises concerns that UMS-arm patients could have been primed to deliver superior results. This problem appears largely unavoidable in this context. ${ }^{2}$ An information intervention cannot plausibly be blinded, and the need to obtain consent to assess patient-reported outcomes would seem to imply that patients must know which arm they are in. However, the lack of statistical significance of several results suggests that future pragmatic trials of drug label changes should be implemented in settings that offer larger sample sizes than those obtained in this study.
The U.S. Pharmacopeial Convention (USP) has developed drug labeling standards in part based on the UMS, and some state pharmacy boards and national pharmacy chains have adopted these standards. Beyond the drug label, patient drug information is provided in the Consumer Medication Information sheet, the package insert, and the medication guide that accompany each prescription. The U.S. Food and Drug Administration (FDA) is working to replace these items with a single, more user-friendly Patient Medication Information form. ${ }^{3}$ Ongoing research on the effectiveness of these new initiatives ${ }^{4,5}$ should provide additional clarity on the value of patient-centered drug information for pharmacists to consider before making wholesale changes to current practice.

Corresponding Author: Fabrice Smieliauskas, $\mathrm{PhD}$; Department of Public Health SciencesUniversity of Chicago, Chicago, IL, USA (e-mail:fsmiel@uchicago.edu).

\section{Compliance with Ethical Standards:}

Conflict of Interest: The author has no conflicts of interest with this article.

\section{REFERENCES}

1. Wolf MS, Shrank WH, Parker RM, et al. A patient-centered prescription drug label to promote appropriate medication use and adherence. $J$ Gen Intern Med. doi: 10.1007/s11606-016-3816-x

2. Ford I, Norrie J. Pragmatic trials. N Engl J Med. 2016;375:454-463.

3. NASEM (National Academies of Sciences, Engineering, and Medicine): Health Literacy: Past, Present, and Future: Workshop Summary. Washington, D.C., National Academies Press, 2015.

4. NABP (National Association of Boards of Pharmacy): Wisconsin Pharmacies Participate in Pilot Project to Help Make Medicine Labels Easier to Read [Internet], 2016[cited 2016 Aug 15] Available from: http://www.nabp.net/ news/wisconsin-pharmacies-participate-in-pilot-project-to-help-make-medicine-labels-easier-to-read

5. Boudewyns V, O'Donoghue AC, Kelly B, et al. Influence of patient medication information format on comprehension and application of medication information: a randomized, controlled experiment. Patient Educ Couns. 2015;98:1592-1599. 